\title{
Periapical Status and Quality of Root Canal Fillings in a Moroccan Subpopulation
}

\author{
Hafsa El Merini, ${ }^{1}$ Hind Amarir, ${ }^{1}$ Amine Lamzawaq, ${ }^{2}$ and Mouna Hamza ${ }^{3}$ \\ ${ }^{1}$ Department of Conservative Dentistry and Endodontics, Faculty of Dentistry, University Hassan II Casablanca, Casablanca, Morocco \\ ${ }^{2}$ Private Practice, Casablanca, Morocco \\ ${ }^{3}$ Department of Statistics, Faculty of Dentistry, University Hassan II Casablanca, Casablanca, Morocco
}

Correspondence should be addressed to Hind Amarir; amarir.hind@gmail.com

Received 3 April 2017; Accepted 25 May 2017; Published 21 June 2017

Academic Editor: Sema Belli

Copyright (c) 2017 Hafsa El Merini et al. This is an open access article distributed under the Creative Commons Attribution License, which permits unrestricted use, distribution, and reproduction in any medium, provided the original work is properly cited.

\begin{abstract}
Aim. The aim of the study was to assess the prevalence of apical periodontitis (AP) and quality of root canal fillings in an adult Moroccan subpopulation. Methods. In the study 508 patients were included, attending the Conservative Dentistry Clinic at the Faculty of Dentistry of Casablanca. 508 panoramic and 709 periapical radiographs were observed. The periapical status of all teeth (with the exception of third molars) was examined according to Ørstavik's periapical index. The statistical analysis was performed with the software Epi Info Version 6.04dfr, April 2001. Results. A total of 12719 teeth were examined. 45.3\% of patients had apical periodontitis. $4.2 \%$ of teeth were treated endodontically and $70.4 \%$ of these treatments were inadequate. $91,5 \%$ with inadequate endodontic treatment presented apical periodontitis, while only $8,2 \%$ with adequate endodontic treatment had apical periodontitis. The lower molars and the upper premolars were the most affected teeth. The presence of apical periodontitis was correlated significantly with insufficient root canal fillings $(p<0.05)$. Conclusions. The present study found a high prevalence of apical periodontitis in this Moroccan population. Inadequate root canal fillings were associated with an increased prevalence of apical periodontitis.
\end{abstract}

\section{Introduction}

Apical periodontitis (AP) is an inflammation disease of periradicular tissues; it occurs as a result of various insults to the dental pulp, including caries and physical and iatrogenic trauma or after a failed endodontic treatment [1-3].

The diagnostic of AP is based on the presence of symptoms and clinical signs during clinical examination and analysis of radiographs (periapical or panoramic). Radiographic analysis is important, because AP in its chronic form is often asymptomatic and left untreated [4].

Endodontic epidemiological studies are necessary because they allow knowing the distribution and the prevalence of AP and its determinants, including treatment outcome in the studied populations which are evaluated by the presence or absence of AP [5].

Several cross-sectional studies have presented data regarding the prevalence of $\mathrm{AP}$ and endodontically treated teeth; these data vary depending on the population studied, the radiographic methods, and the classifications of AP used [6-8].

Data on the prevalence and quality of root canal fillings are rare in Morocco. Considering the fact that these data are important for the evaluation of the quality of the endodontic treatment realized as well as for dental care planning and the need of such information, the aim of this study was to investigate the prevalence and quality of root canal fillings and their association with periapical periodontitis in a group of patients from Morocco.

\section{Materials and Methods}

2.1. Study Population. The sample in this cross-sectional study was formed of patient records. Patients were aged between 10 and 60, attending routine dental treatment (not emergency care) at the University of Casablanca, Faculty of Dentistry, for the first time during the period of May 19, 2014, to June 20, 2014. 
TABLE 1: Distribution of missing teeth, nonrestored teeth, fillings, crowns, endodontically treated teeth, and teeth with apical periodontitis according to tooth type.

\begin{tabular}{|c|c|c|c|c|c|c|}
\hline Tooth group & Missing & Nonrestored & Fillings & Crowns & Endodontically treated teeth & Apical periodontitis \\
\hline \multicolumn{7}{|l|}{ Maxilla } \\
\hline Incisors & $161(5 \%)$ & $18(5.3 \%)$ & $84(12.2 \%)$ & $17(41 \%)$ & $96(17.9 \%)$ & $75(14.2 \%)$ \\
\hline Canines & $124(3.8 \%)$ & $25(7.3 \%)$ & $37(5.4 \%)$ & $7(16.7 \%)$ & $39(7.4 \%)$ & $31(5.9 \%)$ \\
\hline Premolars & $388(12 \%)$ & $71(20.8 \%)$ & $156(22.7 \%)$ & $6(14.8 \%)$ & $140(26 \%)$ & $111(21.1 \%)$ \\
\hline Molars & $1070(33 \%)$ & $81(23.7 \%)$ & $165(24 \%)$ & $3(7.3 \%)$ & $94(17.5 \%)$ & $88(16.7 \%)$ \\
\hline \multicolumn{7}{|l|}{ Mandible } \\
\hline Incisors & $80(2.4 \%)$ & $8(2.3 \%)$ & $6(0.9 \%)$ & $2(5 \%)$ & $4(0.7 \%)$ & $9(1.7 \%)$ \\
\hline Canines & $56(1.8 \%)$ & $17(5 \%)$ & $11(1.6 \%)$ & $1(2.9 \%)$ & $14(2.6 \%)$ & $18(3.4 \%)$ \\
\hline Premolars & $340(10.6 \%)$ & $55(16 \%)$ & $76(11 \%)$ & $2(5 \%)$ & $62(11.5 \%)$ & $61(11.6 \%)$ \\
\hline Molars & $1019(31.4 \%)$ & $67(19.6 \%)$ & $152(22.2 \%)$ & $3(7.3 \%)$ & $88(16.4 \%)$ & $133(25.4 \%)$ \\
\hline Total & $3238(100 \%)$ & $342(100 \%)$ & $687(100 \%)$ & $42(100 \%)$ & $537(100 \%)$ & $526(100 \%)$ \\
\hline
\end{tabular}

2.2. Data Collection. Data were collected retrospectively from the patients' medical records, which include all the information needed for the study, the medical history, and a complete examination of the oral cavity. The data also include panoramic and periapical radiographs.

The information required for our study was recorded in a data collection sheet, including patient name, medical record number, sex, age, missing teeth, nonrestored teeth, fillings, crowns, endodontically treated teeth, and teeth with apical periodontitis.

2.3. Radiographic Evaluation. Teeth were classified as endodontically treated if a radiopaque material was detected in the pulp chamber and/or in one or more of the root canals. Root fillings were classified as adequate or inadequate on the basis of guidelines published by the European Society of Endodontology (ESE) [9]; the technical quality of the root fillings was evaluated according to length from the root apex and homogeneity (adaptation to the canal walls, voids, and porosities). Indeed, the root canal filling was assessed using the following criteria:

(i) Adequate: filling material is present in the root canal within $0-2 \mathrm{~mm}$ of the radiographic apex. Proper density is absence of lateral spaces along root canals or voids.

(ii) Inadequate: root canal fillings end is more than $2 \mathrm{~mm}$ short of the radiographic apex, or extruded beyond the apex, or present only in the pulp chamber. Inadequate also means presence of lateral spaces or voids, inadequate density, unfilled canals, and/or poor condensation.

The periapical health was assessed using the periapical index proposed by Ørstavik et al. [10] in 1986, who scored the apical area of the radiographic images as follows: (1) normal periapical structures; (2) small changes in bone structure; (3) changes in the bone structure with little mineral loss; (4) periodontitis with well-defined radiolucent area; (5) severe periodontitis with exacerbating features. Scores (1) and (2) represented healthy periapical status, while (3), (4), and (5) are signs of AP. Multirooted teeth were classified according to the root with the most severe periapical status.

The parameters used in this study (overall quality of root filling based on length/density of root filling and presence/absence and the degree of AP) were evaluated based on those described by other researchers [11-13].

The radiographs were analyzed by two experienced and calibrated examiners using an illuminated viewer box and magnification $(3,5 \mathrm{x})$.

2.4. Statistical Analysis. After data collection, statistical analysis was performed using Epi Info Version 6.04dfr software. AP was calculated regarding the total number of individuals, the total number of teeth, location, tooth group, and endodontic treatment. Significance level was set at $p<0.05$.

\section{Results}

In a period of one month, from May 19, 2014, to June 20, 2014, a total of 508 panoramic and 709 periapical radiographs were examined, and 12719 teeth were observed.

The sample for this cross-sectional study consisted of 508 patients, with 269 females (53\%) and 239 males (47\%).

From clinical records and X-rays, it was found that the total number of nonrestored teeth was 342 teeth $(2.7 \%), 687$ (5.4\%) with coronal restorations, and only $42(0.3 \%)$ crowned (Table 1).

Endodontic treatment was detected in 537 (4,2\%); the upper premolars had the highest rate with 140 treated teeth (26\%), whereas the teeth with the lowest prevalence were the mandibular incisors with 4 teeth $(0.7 \%)$ (Table 1$)$.

Among the 508 patients in the study population, 230 (45.3\%) had apical periodontitis. AP was observed in 526 teeth (4\%). The most affected were the lower molars with 133 teeth, the upper premolars with 111 teeth, and the upper molars with 88 teeth $(25.4 \%, 21.1 \%$, and $16.7 \%$ resp.) (Table 1$)$.

The total number of teeth with adequate endodontic treatment was 159 (29.6\%); inadequate endodontic treatment was observed in 378 (70.4\%).

13 teeth with adequate treatment (8.2\%) had AP, and 346 teeth with inadequate endodontic treatment (91.5\%) had AP (Table 2). 
TABLE 2: Distribution of apical periodontitis according to the quality of endodontic treatment.

\begin{tabular}{lccc}
\hline Endodontic treatment & $\begin{array}{c}\text { Healthy periodontium } \\
(\mathrm{PAI}=1)\end{array}$ & $\begin{array}{c}\text { Apical periodontitis } \\
\text { (PAI = 2 to 5) }\end{array}$ & Total \\
\hline Adequate & $146(91.8 \%)$ & $13(8.2 \%)$ & $159(100 \%)$ \\
Inadequate & $32(8.5 \%)$ & $346(91.5 \%)$ & $378(100 \%)$ \\
\hline
\end{tabular}

TABLE 3: Distribution of apical periodontitis and healthy periodontium according to the tooth type with endodontic treatment.

\begin{tabular}{|c|c|c|c|c|c|c|}
\hline \multirow{2}{*}{$\begin{array}{l}\text { Tooth type } \\
\text { Maxilla }\end{array}$} & \multicolumn{2}{|c|}{ Number of teeth with endodontic treatment } & \multicolumn{2}{|c|}{$\begin{array}{l}\text { Healthy periodontium } \\
\qquad(\mathrm{PAI}=1)\end{array}$} & \multicolumn{2}{|c|}{$\begin{array}{l}\text { Apical periodontitis } \\
(\mathrm{PAI}=2 \text { to } 5)\end{array}$} \\
\hline & & & & & & \\
\hline Incisors & 96 & $(17.4 \%)$ & 36 & $(20.2 \%)$ & 60 & $(16.7 \%)$ \\
\hline Canines & 39 & $(7.4 \%)$ & 17 & $(9.6 \%)$ & 22 & $(6.2 \%)$ \\
\hline Premolars & 140 & $(26 \%)$ & 49 & $(27.5 \%)$ & 91 & $(25.3 \%)$ \\
\hline Molars & 94 & $(17.5 \%)$ & 30 & $(16.8 \%)$ & 64 & $(17.8 \%)$ \\
\hline \multicolumn{7}{|l|}{ Mandible } \\
\hline Incisors & 4 & $(0.7 \%)$ & 1 & $(0.6 \%)$ & 3 & $(0.8 \%)$ \\
\hline Canines & 14 & $(2.6 \%)$ & 5 & $(2.8 \%)$ & 9 & $(2.5 \%)$ \\
\hline Premolars & 62 & $(11.5 \%)$ & 17 & $(9.6 \%)$ & 45 & $(12.2 \%)$ \\
\hline Molars & 88 & $(16.4 \%)$ & 23 & $(12.9 \%)$ & 65 & $(18.8 \%)$ \\
\hline Total & 537 & $(100 \%)$ & 178 & $(100 \%)$ & 359 & $(100 \%)$ \\
\hline
\end{tabular}

AP was detected in 359 endodontically treated teeth ( $66.8 \%$ of treated teeth); the upper premolars were the most frequent AP affected root-filled teeth (25.3\%) (Table 3).

\section{Discussion}

Chronic, apical periodontitis is an inflammation of the periodontium; it occurs as a result of pulp necrosis and is often discovered as incidental findings on radiographic survey $[1,3,14]$.

A total of 508 panoramic and 709 periapical radiographs were examined. The periapical radiographs were systematically performed whenever a panoramic X-ray showed a tooth, a coronary, or radicular obturation with suspicion of a periapical lesion. The records of patients, whose radiographic examinations could not be made, regardless of the cause, were excluded from the study. Although panoramic radiographs provide a general overview of dentomaxilomandibular structures, periapical radiographs had higher definition and yielded more information on the status of the periapical bone [15], so periapical radiographs were used in this study mainly to evaluate the degrees of apical periodontitis and the quality of the endodontic treatments.

Previous studies had already used the same techniques for the same reasons [16-20]. Other epidemiological studies $[21,22]$ concluded that the use of panoramic radiography in epidemiologic studies of dental health was acceptable; Muhammed and Manson-Hing [23] found no statistically significant difference between panoramic and periapical radiographs in the detection of AP.

Recently, a new imaging modality, cone beam computed tomography (CBCT), has been shown to be a useful tool in a number of endodontic applications. This 3-dimensional imaging technique allows for a more precise diagnosis of periapical lesions [24]. However, the higher effective dose of ionizing radiation compared to conventional 2-dimensional radiographs is rarely justified. Some scientists have suggested the use of CBCT when conducting future research, in order to minimize the technical limitations of conventional radiographs, especially when new scanners with lower radiation doses are available $[25,26]$.

In order to evaluate the periapical status, the periapical index (PAI) developed by Ørstavik et al. [10] was adopted. PAI is a scoring system for radiographic assessment of apical periodontitis which presents good accuracy and reproducibility [27].

The sample contained more females (53\%) than males (47\%). This difference is not significant except the fact that women are more healthcare conscious than males and have a greater interest in receiving dental care. Other studies in this field found a similar gender proportion [18, 28-30].

In a sample of 508 patients, 230 (45.3\%) had apical periodontitis. This prevalence is lower than that found by Chala et al. (63.79\%) [31], which was the only study carried out in Morocco, at dental clinic of Rabat University. The prevalence found is higher than that reported by Georgopoulou et al. $(13,6 \%)$ [29] and Loftus et al. (33\%) [28]. On the other hand, it remains lower than that found by Boucher et al. (63\%) [16], Jiménez-Pinzón et al. (61\%) [18], and De Moor et al. (73\%) [32]. This difference in the prevalence of apical periodontitis observed between our study and other studies could be explained by the difference in methodology and difference in oral health policies between countries.

526 teeth (4.1\%) had apical periodontitis, the most affected teeth were the lower molars (25.4\%), which corroborates the results of Peters et al. [33], who found that the highest 
prevalence of apical periodontitis occurred in the second mandibular molars (16.9\%), followed by the first mandibular molars (13\%).

537 teeth $(4.2 \%)$ had undergone root canal treatment, with a ratio of one tooth being treated endodontically per patient. This rate is lower than that found by Matijević et al. (8.5\%) [11], Ilić et al. (12.5\%) [12], and Boucher et al. (19\%) [16], almost similar to that declared by Peters et al. (4.8\%) [33], and higher than that found by Jiménez-Pinzón et al. (2.4\%) [18].

The upper premolars are the most frequently treated teeth in our survey. The distribution of root canal treatment according to the tooth type was analyzed in many studies; the findings are very diverse [12].

The relationship between the quality of endodontic treatment and the prevalence of apical periodontitis has been demonstrated in a large number of epidemiological studies $[11,16,34-37]$. The present work showed that more than twothirds of root canal-treated teeth $(66.8 \%)$ presented apical periodontitis. This rate is higher than that found by Chala et al. in Morocco (39.5\%) [31] and other studies in Saudi Arabia (58.6\%) [34], France (33\%) [13], Brazil (16.70\%) [38], and Palestine 59.5\% [39].

Quality of root canal filling is one of the keys of the success of endodontic treatment. In our study, same as in other comparable studies, the quality of the root canal filling is estimated by two criteria: the length of the root canal filling from the radiographic apex $(0-2 \mathrm{~mm})$ and the appearance of the canal obturation in terms of density and tightness. The results of the present study showed that only $29.6 \%$ of endodontic treatments were adequate, which confirmed the results of other surveys that showed that a large percentage of root canal fillings were not acceptable [32, 40, 41].

High frequency of AP in teeth with inadequate root canal fillings has been reported in several previous studies [27, 36, $42,43]$. In this study, inadequate treatments were associated with a significantly high prevalence of periodontitis; $91.5 \%$ of inadequate endodontic treatments had apical periodontitis and only $8.5 \%$ of the appropriate treatments presented AP.

\section{Conclusion}

The frequency of AP in endodontically treated teeth of this patient group was high, especially in teeth with inadequate root fillings, demonstrating that the quality of endodontic treatment is a factor associated with the appearance of apical periodontitis.

\section{Conflicts of Interest}

The authors declare that there are no conflicts of interest regarding the publication of this paper.

\section{Acknowledgments}

The authors express their sincere gratitude to the deceased Professor Khadija Lahlou for her valuable contribution to this study.

\section{References}

[1] P. N. R. Nair, "Apical periodontitis: a dynamic encounter between root canal infection and host response," Periodontology 2000, vol. 14, no. 1, pp. 121-148, 1997.

[2] D. Ricucci and J. F. Siqueira Jr., "Biofilms and apical periodontitis: study of prevalence and association with clinical and histopathologic findings," Journal of Endodontics, vol. 36, no. 8, pp. 1277-1288, 2010.

[3] D. Orstavik and T. P. Ford, Essential Endodontology. Prevention and treatment of Apical Periodontitis, vol. 410, Blackwell Science Ltd., Oxford, UK, 1998.

[4] C. A. Murray and W. P. Saunders, "Root canal treatment and general health: A review of the literature," International Endodontic Journal, vol. 33, no. 1, pp. 1-18, 2000.

[5] H. M. Eriksen, L. Kirkevang, and K. Petersson, "Endodontic epidemiology and treatment outcome: general considerations," Endodontic Topics, vol. 2, no. 1, pp. 1-9, 2002.

[6] L.-L. Kirkevang, P. Hörsted-Bindslev, D. Ørstavik, and A. Wenzel, "Frequency and distribution of endodontically treated teeth and apical periodontitis in an urban Danish population," International Endodontic Journal, vol. 34, no. 3, pp. 198-205, 2001.

[7] N. N. Dugas, H. P. Lawrence, P. E. Teplitsky, M. J. Pharoah, and S. Friedman, "Periapical health and treatment quality assessment of root-filled teeth in two Canadian populations," International Endodontic Journal, vol. 36, no. 3, pp. 181-192, 2003.

[8] J. J. Segura-Egea, A. Jiménez-Pinzón, J. V. Ríos-Santos, E. Velasco-Ortega, R. Cisneros-Cabello, and M. M. PoyatoFerrera, "High prevalence of apical periodontitis amongst smokers in a sample of Spanish adults," International Endodontic Journal, vol. 41, no. 4, pp. 310-316, 2008.

[9] European Society of Endodontology, "Consensus report of the European Society of Endodontology on quality guidelines for endodontic treatment," International Endodontic Journal, vol. 27, no. 3, pp. 115-124, 1994.

[10] D. Ørstavik, K. Kerekes, and H. M. Eriksen, “The periapical index: A scoring system for radiographic assessment of apical periodontitis," Dental Traumatology, vol. 2, no. 1, pp. 20-34, 1986.

[11] J. Matijević, T. Č. Dadić, G. P. Mehičić, I. Anić, M. Šlaj, and S. J. Krmek, "Prevalence of apical periodontitis and quality of root canal fillings in population of Zagreb, Croatia: a crosssectional study," Croatian Medical Journal, vol. 52, no. 6, pp. 679-687, 2011.

[12] J. Ilić, M. Vujašković, L. Tihaček-Šojić, and A. Milić-Lemić, "Frequency and quality of root canal fillings in an adult serbian population," Srpski Arhiv za Celokupno Lekarstvo, vol. 142, no. 11-12, pp. 663-668, 2014.

[13] P. B. L. Tavares, E. Bonte, T. Boukpessi, J. F. Siqueira Jr., and J.J. Lasfargues, "Prevalence of apical periodontitis in root canaltreated teeth from an urban French population: influence of the quality of root canal fillings and coronal restorations," Journal of Endodontics, vol. 35, no. 6, pp. 810-813, 2009.

[14] H. O. Trowbridge and R. C. Emling, Inflammation. A Review of the Process, Quintessence Books, Chicago, Ill, USA, Fifth edition, 1997.

[15] M. Rohlin, B. Kullendorff, M. Ahlqwist, C. O. Henrikson, L. Hollender, and B. Stenström, "Comparison between panoramic and periapical radiography in the diagnosis of periapical bone lesions," Dentomaxillofacial Radiology, vol. 18, no. 4, pp. 151-155, 1989. 
[16] Y. Boucher, L. Matossian, F. Rilliard, and P. Machtou, "Radiographic evaluation of the prevalence and technical quality of root canal treatment in a French subpopulation," International Endodontic Journal, vol. 35, no. 3, pp. 229-238, 2002.

[17] R. J. De Cleen, A. H. Schuurs, P. R. Wesselink, and M. K. WU, "Periapical status and prevalence of endodontic treatment in an adult Dutch population," International Endodontic Journal, vol. 26, no. 2, pp. 112-119, 1993.

[18] A. Jiménez-Pinzón, J. J. Segura-Egea, M. Poyato-Ferrera, E. Velasco-Ortega, and J. V. Ríos-Santos, "Prevalence of apical periodontitis and frequency of root-filled teeth in an adult Spanish population," International Endodontic Journal, vol. 37, no. 3, pp. 167-173, 2004.

[19] B. Ödesjö, L. Helldén, L. Salonen, and K. Langeland, "Prevalence of previous endodontic treatment, technical standard and occurrence of periapical lesions in a randomly selected adult, general population," Dental Traumatology, vol. 6, no. 6, pp. 265272, 1990.

[20] K. Petersson, B. Lewin, J. Hakansson, B. Olsson, and A. Wennberg, "Endodontic status and suggested treatment in a population requiring substantial dental care," Dental Traumatology, vol. 5, no. 3, pp. 153-158, 1989.

[21] H. A. Ray and M. Trope, "Periapical status of endodontically treated teeth in relation to the technical quality of the root filling and the coronal restoration," International Endodontic journal, vol. 28, no. 1, pp. 12-18, 1995.

[22] M. Ahlquist, A. Halling, and L. Hollender, "Rotational panoramic radiography in epidemiological studies of dental health," Swedish Dental Journal, vol. 10, pp. 79-84, 1986.

[23] A. H. Muhammed and L. R. Manson-Hing, "A comparison of panoramic and intraoral radiographic surveys in evaluating a dental clinic population," Oral Surgery, Oral Medicine, Oral Pathology, vol. 54, no. 1, pp. 108-117, 1982.

[24] F. B. Jeger, A. Lussi, M. M. Bornstein, R. Jacobs, and S. F. Janner, "Cone beam computed tomography in endodontics: a review for daily clinical practice," Schweiz Monatsschr Zahnmed, vol. 123, no. 7-8, pp. 661-668, 2013.

[25] T. Venskutonis, G. Plotino, G. Juodzbalys, and L. Mickevičiene, "The importance of cone-beam computed tomography in the management of endodontic problems: a review of the literature," Journal of Endodontics, vol. 40, no. 12, pp. 1895-1901, 2014.

[26] F. Rutz da Silva, E. Z. Padilha, V. S. Cândido, R. Cavassim, A. C. Pereira, and E. Hebling, "Relationship between quality of root canal obturation and periapical lesion in elderly patients: a systematic review," Gerodontology, vol. 33, no. 3, pp. 290-298, 2016.

[27] C. Estrela, C. R. Leles, A. C. B. Hollanda, M. S. Moura, and J. D. Pécora, "Prevalence and risk factors of apical periodontitis in endodontically treated teeth in a selected population of Brazilian adults," Brazilian Dental Journal, vol. 19, no. 1, pp. 3439, 2008.

[28] J. J. Loftus, A. P. Keating, and B. E. McCartan, "Periapical status and quality of endodontic treatment in an adult Irish population," International Endodontic Journal, vol. 38, no. 2, pp. 81-86, 2005.

[29] M. K. Georgopoulou, A. P. Spanaki-Voreadi, N. Pantazis, and E. G. Kontakiotis, "Frequency and distribution of root filled teeth and apical periodontitis in a Greek population," International Endodontic Journal, vol. 38, no. 2, pp. 105-111, 2005.

[30] K. Gulsahi, A. Gulsahi, M. Ungor, and Y. Genc, "Frequency of root-filled teeth and prevalence of apical periodontitis in an adult Turkish population," International Endodontic Journal, vol. 41, no. 1, pp. 78-85, 2008.

[31] S. Chala, R. Abouqal, and F. Abdallaoui, "Prevalence of apical periodontitis and factors associated with the periradicular status," Acta Odontologica Scandinavica, vol. 69, no. 6, pp. 355359, 2011

[32] R. J. G. De Moor, G. M. G. Hommez, J. G. de Boever, K. I. M. Delmé, and G. E. I. Martens, "Periapical health related to the quality of root canal treatment in a Belgian population," International Endodontic Journal, vol. 33, no. 2, pp. 113-120, 2000.

[33] L. B. Peters, J. A. Lindeboom, M. E. Elst, and P. R. Wesselink, "Prevalence of apical periodontitis relative to endodontic treatment in an adult Dutch population: A repeated crosssectional study," Oral Surgery, Oral Medicine, Oral Pathology, Oral Radiology and Endodontology, vol. 111, no. 4, pp. 523-528, 2011.

[34] K. Alfouzan, J. K. U. Baskaradoss, A. Geevarghese, M. Alzahrani, and K. Alhezaimi, "Radiographic diagnosis of periapical status and quality of root canal fillings in a Saudi Arabian subpopulation," Oral Health \& Preventive Dentistry, vol. 14, no. 3, pp. 241-248, 2016.

[35] R. Weiger, S. Hitzler, G. Hermle, and C. Lost, "Periapical status, quality of root canal fillings and estimated endodontic treatment needs in an urban German population," Dental Traumatology, vol. 13, no. 2, pp. 69-74, 1997.

[36] Y. Zhong, J. Chasen, R. Yamanaka et al., "Extension and density of root fillings and postoperative apical radiolucencies in the veterans affairs dental longitudinal study," Journal of Endodontics, vol. 34, no. 7, pp. 798-803, 2008.

[37] M. Tsuneishi, T. Yamamoto, R. Yamanaka et al., "Radiographic evaluation of periapical status and prevalence of endodontic treatment in an adult Japanese population," Oral Surgery, Oral Medicine, Oral Pathology, Oral Radiology and Endodontology, vol. 100, no. 5, pp. 631-635, 2005.

[38] T. Berlinck, J. M. Tinoco, F. L. Carvalho, L. M. Sassone, and E. M. Tinoco, "Epidemiological evaluation of apical periodontitis prevalence in an urban Brazilian population," Brazilian Oral Research, vol. 29, no. 1, article 51, 2015.

[39] R. Mukhaimer, E. Hussein, and I. Orafi, "Prevalence of apical periodontitis and quality of root canal treatment in an adult Palestinian sub-population," Saudi Dental Journal, vol. 24, no. 3-4, pp. 149-155, 2012.

[40] J. J. Segura-Egea, A. Jiménez-Pinzón, M. Poyato-Ferrera, E. Velasco-Ortega, and J. V. Ríos-Santos, "Periapical status and quality of root fillings and coronal restorations in an adult Spanish population," International Endodontic Journal, vol. 37, no. 8, pp. 525-530, 2004.

[41] R. Salehrabi and I. Rotstein, "Endodontic treatment outcomes in a large patient population in the USA: an epidemiological study," Journal of Endodontics, vol. 30, no. 12, pp. 846-850, 2004.

[42] M. Song, M. Park, C.-Y. Lee, and E. Kim, "Periapical status related to the quality of coronal restorations and root fillings in a Korean population," Journal of Endodontics, vol. 40, no. 2, pp. 182-186, 2014.

[43] F. Frisk, A. Hugoson, and M. Hakeberg, "Technical quality of root fillings and periapical status in root filled teeth in Jönköping, Sweden," International Endodontic Journal, vol. 41, no. 11, pp. 958-968, 2008. 


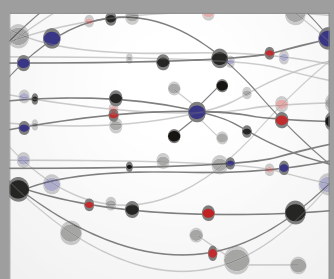

The Scientific World Journal
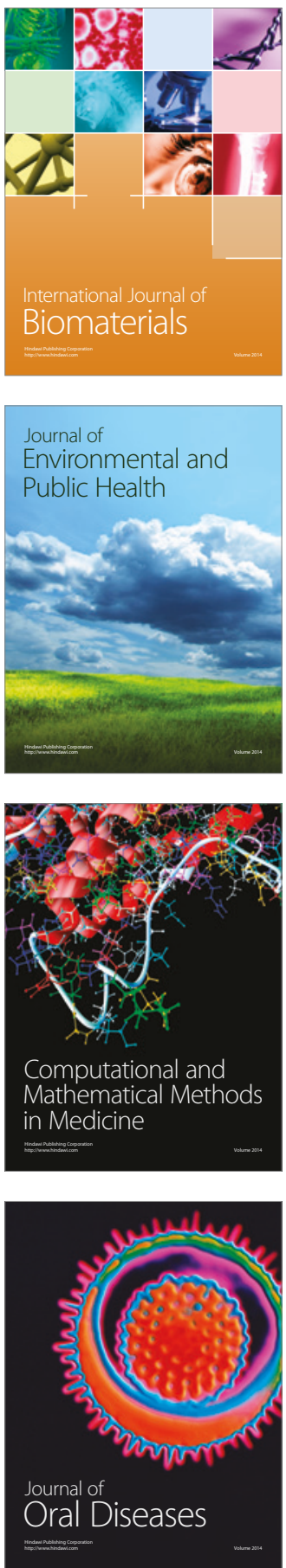
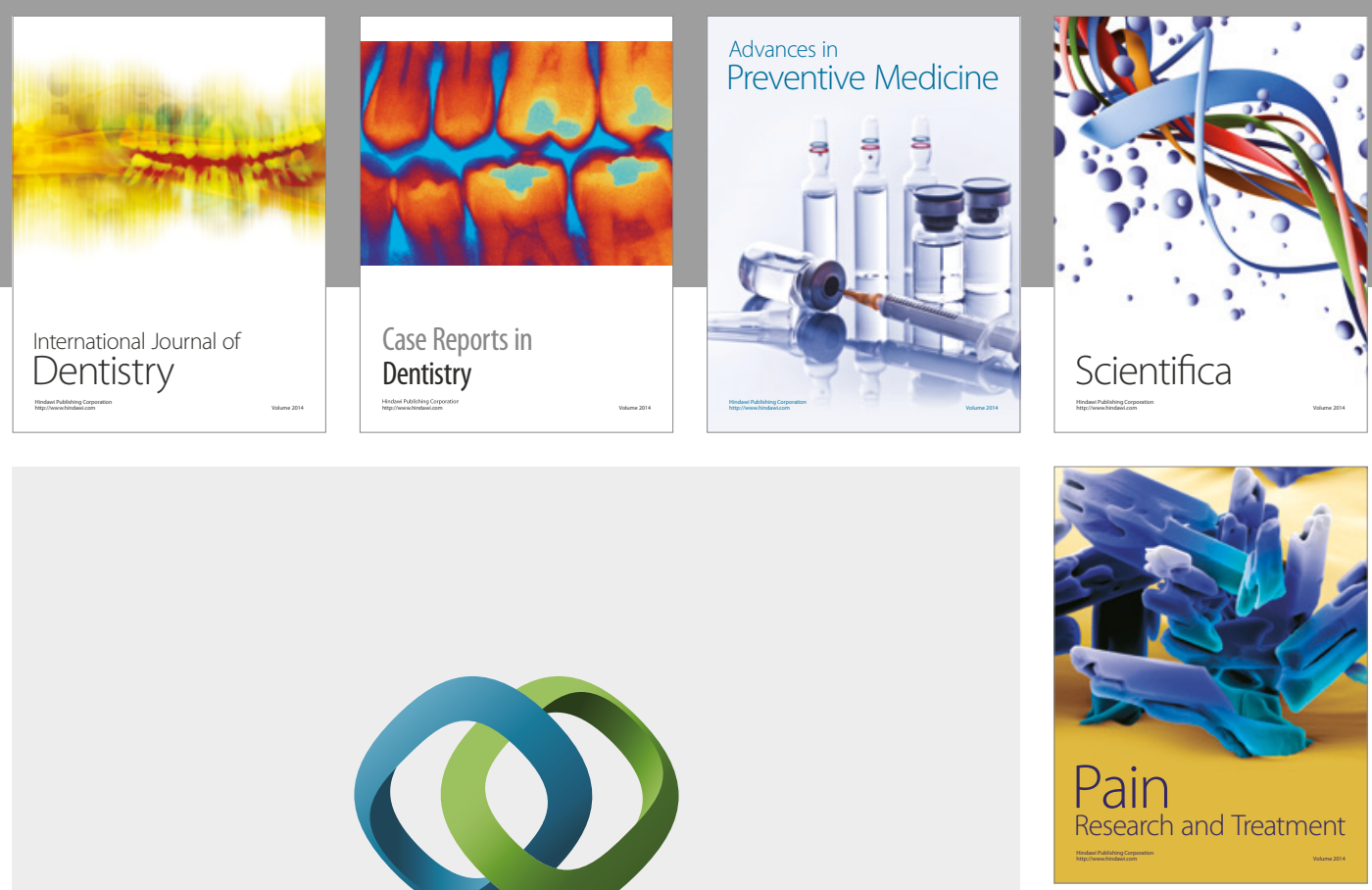

\section{Hindawi}

Submit your manuscripts at

https://www.hindawi.com
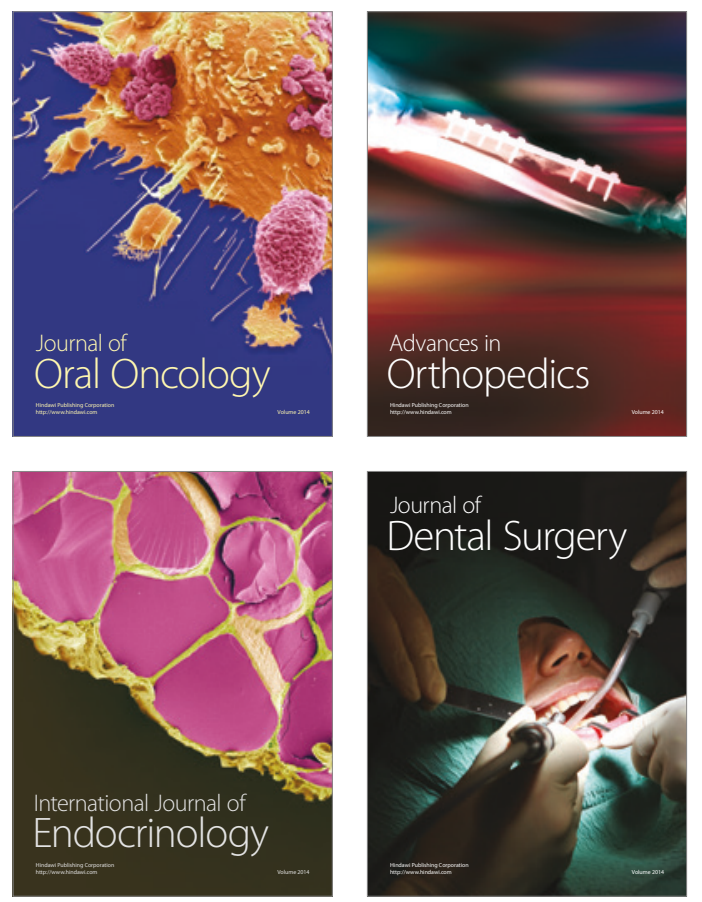
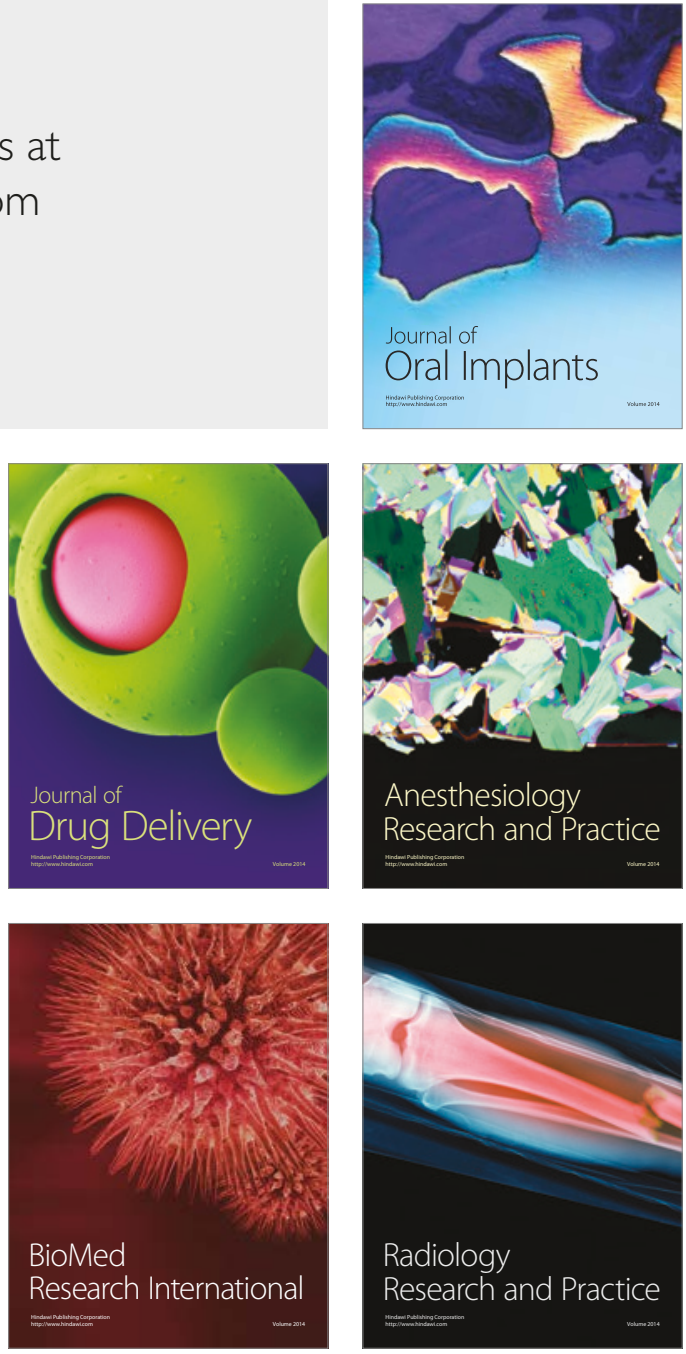